\title{
Dense lying self-organized GaAsSb quantum dots on GaAs for efficient lasers
}

\author{
Thomas H. Loeber*, Dirk Hoffmann and Henning Fouckhardt
}

\author{
Full Research Paper \\ Address: \\ Optoelectronics and Microoptics Research Group, Physics \\ Department, Kaiserslautern University of Technology, P.O. Box 3049, \\ D-67653 Kaiserslautern, Germany \\ Email: \\ Thomas H. Loeber ${ }^{*}$ - loeber@physik.uni-kl.de \\ ${ }^{*}$ Corresponding author \\ Keywords: \\ V/III flux ratio; GaSb quantum dots; growth temperature; \\ semiconductor laser; Stranski-Krastanov growth
}

Beilstein J. Nanotechnol. 2011, 2, 333-338.

doi:10.3762/bjnano.2.39

Received: 20 December 2010

Accepted: 27 May 2011

Published: 30 June 2011

Associate Editor: P. Leiderer

() 2011 Loeber et al; licensee Beilstein-Institut.

License and terms: see end of document.

\begin{abstract}
GaAsSb quantum dots (QDs) were grown on GaAs in the Stranski-Krastanov (SK) epitaxial mode. Their characteristics were dependent on the $\mathrm{Sb} / \mathrm{Ga}(\mathrm{V} / \mathrm{III})$ flux ratio and the growth temperature. The samples were grown with a V/III ratio between $0.45 / 1$ and 1.50/1 and a temperature between 445 and $580{ }^{\circ} \mathrm{C}$, not commonly used by other research groups. These parameters enabled the growth of dense lying dots with a density at least up to $6.5 \times 10^{10} \mathrm{~cm}^{-2}$ and a diameter and height of 20 and $4 \mathrm{~nm}$, respectively. The photoluminescence (PL) spectra revealed a QD peak at an emission wavelength between $\lambda=0.876$ and $1.035 \mu \mathrm{m}$, depending on the exact conditions. Using a stack of such QD layers, an electrically pumped efficient QD laser was realized with an emission wavelength of $\lambda \approx 0.900 \mu \mathrm{m}$ at a temperature of $84 \mathrm{~K}$.
\end{abstract}

\section{Introduction}

GaSb quantum dots (QDs) grown on GaAs wafers have received considerable attention in efforts to improve the efficiency of near- and mid-infrared antimonide lasers in the emission wavelength range between 1.0 and $1.5 \mu \mathrm{m}$ [1]. The lattice mismatch of $7.8 \%$ between $\mathrm{GaSb}$ and GaAs (similar to that of InAs and GaAs) causes Stranski-Krastanov (SK) growth, depending on the precise control of the $\mathrm{Sb} / \mathrm{Ga} \mathrm{V} / \mathrm{III}$ flux ratio, coverage, and growth temperature. Furthermore these parameters influence dot shape, size and density. The staggered (typeII) band alignment with a large valence band offset provides hole confinement. The electronic states lie in the GaAs conduc- tion band continuum [1,2]. Bimberg et al. grew GaSb on GaAs with variable GaSb layer thickness [2-5]. Huffaker et al. achieved QDs by variation of the $\mathrm{Sb} / \mathrm{Ga}$ flux ratio (V/III ratio) between $1.00 / 1$ and 6.50/1 with a maximum dot density around $2.9 \times 10^{10} \mathrm{~cm}^{-2}[1,6-9]$. These samples were grown at a temperature of $T \approx 500{ }^{\circ} \mathrm{C}$. So far, photoluminescence (PL) signals of SK-grown GaSb QDs on GaAs have emerged at a wavelength between 1.0 and $1.3 \mu \mathrm{m}$ [7,9]. The interface between the GaAs buffer and the GaSb QDs can cause a wetting layer, which will lead to an additional PL peak with an even smaller wavelength around $0.92 \mu \mathrm{m}[2,3,7]$. 
In this paper we report on SK-grown QDs with a V/III ratio between $0.45 / 1$ and $1.50 / 1$ to find the optimum dot density and size at constant coverage and growth temperature of $T=527^{\circ} \mathrm{C}$. In several steps the ratio was increased from sample to sample, and the dot density was characterized with atomic force microscopy (AFM). Moreover, the PL peak of the QDs was shifted by varying the growth temperature $T$ between 445 and $583{ }^{\circ} \mathrm{C}$. For this very growth series two $\mathrm{Sb} / \mathrm{Ga}$ ratios, i.e., 1.0/1 and $1.5 / 1$, were chosen. In our case an additional peak attributed to a possible wetting layer could not be identified.

An electrically pumped QD laser was grown with an active region consisting of eight layers of QDs and an emission wavelength of $\lambda \approx 0.900 \mu \mathrm{m}$.

\section{Results and Discussion Growth procedure and dot characterization}

All samples were grown on (001) GaAs substrates with an R450 molecular beam epitaxy (MBE) system from DCA Oy, Finland. The flux was determined by beam equivalent pressures (BEP) for all source materials. The partial Ga pressure was kept nearly constant between $\approx 1.60$ and $\approx 1.89 \times 10^{-7} \mathrm{hPa}$, for each individual growth process. Depending on the measured Ga flux, the $\mathrm{Sb}$ flux was set with a valved $\mathrm{Sb}$ cracker.

An $\approx 200 \mathrm{~nm}$ thick GaAs layer was grown as a buffer on each substrate with standard techniques at a growth temperature around $T=640{ }^{\circ} \mathrm{C}$. Then, the samples were cooled down to the desired QD growth temperature of $T=527^{\circ} \mathrm{C}$ under As flux. The GaSb QDs were grown on an As-rich surface. The nominal coverage for all samples was 3 monolayers (ML) with a growth rate of $\approx 0.3 \mathrm{ML} / \mathrm{s}$.

The samples were cooled down to room temperature under the adjusted Sb flux immediately after the QD growth for topographic tapping-mode measurements with a Park XE-70 AFM and soft cantilevers. In contrast, for PL measurements the samples were capped with an epitaxial $\approx 90 \mathrm{~nm}$ thick GaAs layer without growth interruption, at the GaSb growth temperature, and then cooled down under As flux. During PL measurements, the samples could be cooled down to a temperature $T_{\mathrm{PL}}=20 \mathrm{~K}$ and heated up in a controlled way. They were excited by a diode laser at $\lambda=780 \mathrm{~nm}$ with a maximum intensity of $70 \mathrm{~W} / \mathrm{cm}^{2}$ entering the sample. Unless otherwise stated the PL measurements were performed at $T_{\mathrm{PL}}=20 \mathrm{~K}$.

Figure 1a and $1 \mathrm{~b}$ show exemplary AFM images of two samples both grown at the same temperature of $T=527^{\circ} \mathrm{C}$, but with different $\mathrm{Sb}$ flux. The V/III ratio was $1.00 / 1$ for the sample in a) and $1.50 / 1$ for the sample in $b$ ). As can be seen from the diagram in Figure 1c, with the V/III ratio increasing from 0.45/1 up to $1.00 / 1$ the dot density increased from 2.9 to $6.5 \times 10^{10} \mathrm{~cm}^{-2}$. (An even higher dot density of $10 \times 10^{10} \mathrm{~cm}^{-2}$ could be achieved for a nominal coverage of $5 \mathrm{ML}$, but in this case the dots start to join at their base.)

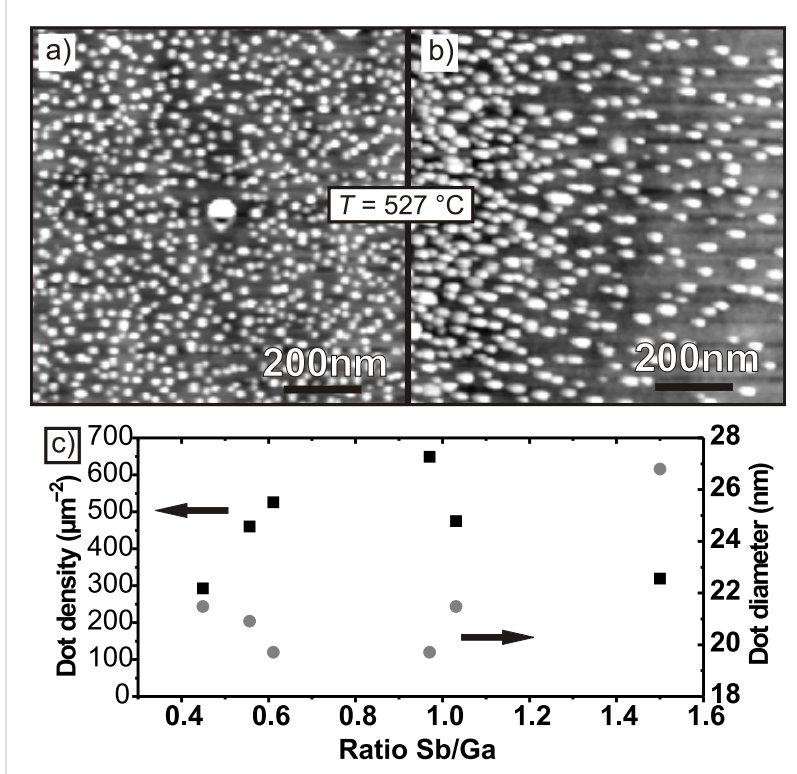

Figure 1: Top: AFM images of samples grown at a temperature of $T=527^{\circ} \mathrm{C}$ and a nominal coverage of $3 \mathrm{ML}$, but with different V/III ratios: a) $0.97 / 1$ and b) $1.5 / 1$; c) dot density and diameter plotted against $\mathrm{V} / \mathrm{III}$ ratio.

For a nominal coverage of $3 \mathrm{ML}$, the dot shape, average height $h=5 \pm 1 \mathrm{~nm}$ and average diameter $d=20 \pm 1 \mathrm{~nm}$ were nearly constant for all the $\mathrm{V} / \mathrm{III}$ ratios between $0.45 / 1$ up to $1.00 / 1$.

The dot dimensions were almost homogenous across the wafer except for a few much bigger dots (e.g., at the center of Figure 1a). The density of these bigger isolated islands was much lower $\left(0.01 \times 10^{10} \mathrm{~cm}^{-2}\right)$ and thus they did not greatly affect the measurement results.

When the V/III ratio was increased further, from 1.00/1 up to $1.50 / 1$, the dot density decreased from $6.5 \times 10^{10}$ down to $3.2 \times 10^{10} \mathrm{~cm}^{-2}$, while the dot height increased from $h=5 \pm 1 \mathrm{~nm}$ to $7 \pm 1 \mathrm{~nm}$ and the diameter enlarged from $d=20 \pm 1 \mathrm{~nm}$ to $27 \pm 1 \mathrm{~nm}$. So-called smaller dots became so-called larger dots. Apparently, a V/III ratio of 1/1 is optimal for high quantum dot density. Compared to the highest QD density previously reported, our results reveal a two times higher density.

Figure 2 shows the PL spectra of two QD samples grown at a V/III ratio of 1/1 (so-called smaller dots) and 1.5/1 (larger dots), respectively, at a growth temperature of $T=527{ }^{\circ} \mathrm{C}$ and a 
nominal coverage of $3 \mathrm{ML}$. The peak maximum is at $\lambda_{1 / 1}=0.887 \mu \mathrm{m}$ with a full width at half maximum (FWHM) of $15 \mathrm{~nm}$ for the smaller dots. An additional peak on the right shoulder with a wavelength of $0.912 \mu \mathrm{m}$ can be assigned to the bigger isolated islands. The larger dots emit at $\lambda_{1.5 / 1}=1.034 \mu \mathrm{m}$ with a FWHM of $58 \mathrm{~nm}$. This last peak is similar in position to those PL peaks reported in [1,6-9], [2,3,5,10] or [11,12], although the dot dimensions are larger in our case. In other publications a peak below $\lambda=1 \mu \mathrm{m}$ has also been assigned to QD emission [13-16]. As seen from the difference between $\lambda_{1 / 1}$ and $\lambda_{1.5 / 1}$ a variation of the dot size by several nanometers, achieved via a change of the V/III ratio, already leads to a shift of the spectral position of the PL peak by $\approx 150 \mathrm{~nm}$.

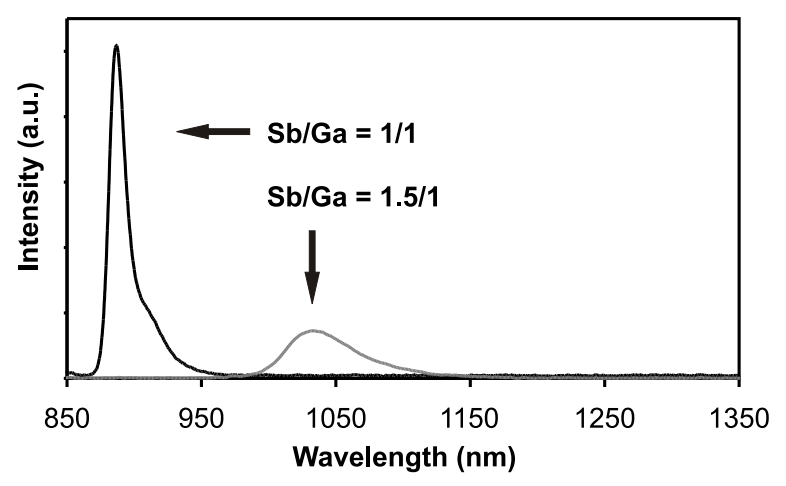

Figure 2: PL spectra of GaSb dots grown on GaAs with two different V/III ratios of $1.5 / 1$ and $1 / 1$, respectively, at a growth temperature of $T=527^{\circ} \mathrm{C}$ and a nominal coverage of $3 \mathrm{ML}$.

The PL spectra were recorded at different PL sample temperatures from $T_{\mathrm{PL}}=20$ to $200 \mathrm{~K}$ in steps of $30 \mathrm{~K}$. At higher temperatures no PL peak could be identified. In Figure 3 the wavelength of the PL peak maximum is plotted against the PL temperature $T_{\mathrm{PL}}$. For the smaller dots the wavelength increases slightly from 0.887 up to $0.903 \mu \mathrm{m}$ for increasing sample temperature $T_{\mathrm{PL}}$, giving a value of $0.08 \mathrm{~nm} / \mathrm{K}$ for the temperature dependent peak shift. The FWHM is almost constant at $18 \pm 3 \mathrm{~nm}$. The peak of the larger dots shifts from 1.034 up to $1.059 \mu \mathrm{m}$, giving $0.14 \mathrm{~nm} / \mathrm{K}$, with a FWHM of $75 \pm 16 \mathrm{~nm}$. The weaker quantization in the larger dots leads to a stronger temperature dependence. But the latter is still smaller than that of a $50 \mathrm{~nm}$ thin GaSb quantum well (between $100 \mathrm{~nm}$ thick $\mathrm{AlAs}_{0.084} \mathrm{Sb}_{0.916}$ barriers) with $0.35 \mathrm{~nm} / \mathrm{K}$ (measured PL peak shifts from 1.533 to $1.594 \mu \mathrm{m}$ for $T_{\mathrm{PL}}=20$ to $200 \mathrm{~K}$ ). These results justify the conclusion that our dots have QD character. With increasing excitation power density up to the maximum of $70 \mathrm{~W} / \mathrm{cm}^{2}$, the well-known blueshift was observed for both kinds of dots [2]. For the smaller dots the wavelength decreases from 0.893 down to $0.887 \mu \mathrm{m}$, while the peak for the larger dots shifts from 1.049 down to $1.034 \mu \mathrm{m}$.

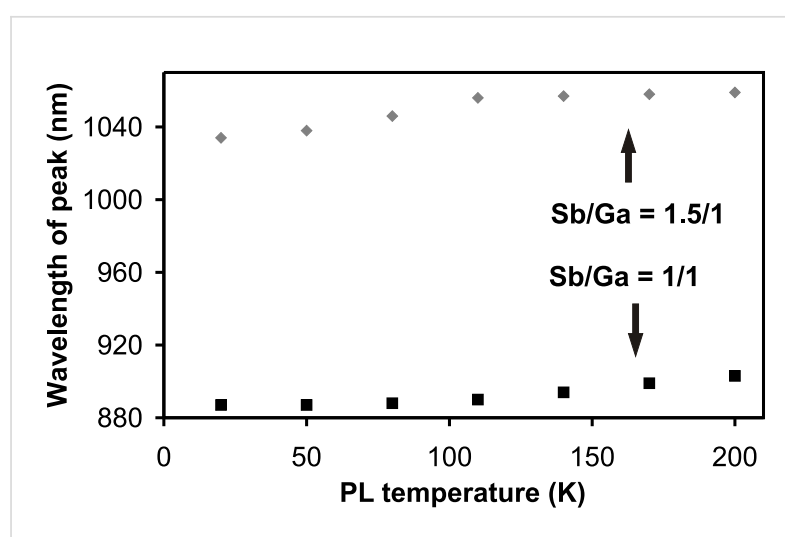

Figure 3: PL peak position for dots with larger diameter (at a V/III ratio $1.5 / 1$ ) and smaller diameter (at a V/III ratio 1/1) plotted against sample temperature $T_{\mathrm{PL}}$.

The smaller dots have the same dimension as those mentioned by other authors, but they emit at a $\approx 250 \mathrm{~nm}$ lower wavelength [1-5,7-12]. This deviation is due to an incorporation of arsenic (As) within the GaSb QDs, due to the higher growth temperatures as compared to $[10,15,17,18]$ and the lower $\mathrm{Sb} / \mathrm{Ga}$ ratio. So the QDs actually consist of the alloy $\mathrm{GaAs}_{1-x} \mathrm{Sb}_{x}$. With decreasing Sb concentration within the QDs the emission wavelength decreased.

To estimate the actual $\mathrm{Sb}$ concentration within the QDs, numerical simulations were performed with the program nextnano ${ }^{3}$ [19]. For the calculations, the dot dimensions were taken from AFM measurements. The simulations are in good agreement with the experimental data for $x=0.28 \pm 0.07\left(\mathrm{GaAs}_{0.72} \mathrm{Sb}_{0.28}\right)$ in case of the smaller dots and for $x=0.52 \pm 0.03$ $\left(\mathrm{GaAs}_{0.48} \mathrm{Sb}_{0.52}\right)$ in case of the larger dots. A higher $\mathrm{Sb} / \mathrm{Ga}$ ratio during the growth process leads to a higher $\mathrm{Sb}$ concentration within the QDs and to larger dots. Both effects result in a higher emission wavelength for the larger dots.

As stated above at our higher growth temperature more As can diffuse into the QDs and lead to a decrease in the Sb concentration. Our dots were grown at a temperature $\approx 30^{\circ} \mathrm{C}$ higher than in [1-5,7-12], which could explain the blueshift of $\approx 250 \mathrm{~nm}$. To further test this assumption, QDs were grown at different growth temperatures. The V/III ratio was kept constant at 1/1 for smaller dots or 1.5/1 for larger dots. The growth temperature was varied from $\approx 445$ up to $\approx 580{ }^{\circ} \mathrm{C}$. Figure 4 shows the corresponding PL spectra. For the samples grown at a V/III ratio of $1 / 1$ the maximum wavelength was $\lambda_{1 / 1, \max }=0.948 \mu \mathrm{m}$ at $T=480^{\circ} \mathrm{C}$. No samples with higher wavelengths were observed for this ratio [20]. The minimum wavelength $\lambda_{1 / 1, \min }=0.876 \mu \mathrm{m}$ was achieved for $T=575^{\circ} \mathrm{C}$. Samples with a V/III ratio of 1.5/1 emitted at a maximum wavelength of $\lambda_{1.5 / 1, \max }=1.035 \mu \mathrm{m}$ for a growth temperature of $T=527^{\circ} \mathrm{C}$. 
Samples grown at a lower temperature showed no well-defined PL peak. The minimum wavelength $\lambda_{1.5 / 1, \text { min }}=0.943 \mu \mathrm{m}$ for the larger dots was achieved at the highest growth temperature of $T=583{ }^{\circ} \mathrm{C}$. This wavelength is almost equal to the maximum wavelength $\lambda_{1 / 1 \text {,max }}$ of the smaller dots. With increasing growth temperature the PL peak shifts continuously towards smaller wavelengths for both kinds of dots. Altogether the emission wavelength of the QDs can be adjusted in a wide range continuously from $\lambda_{1 / 1, \min }=0.876 \mu \mathrm{m}$ up to $\lambda_{1.5 / 1, \max }=1.035 \mu \mathrm{m}$ by changing V/III ratio and growth temperature. (With further change of the nominal coverage it should be possible to increase the emission wavelength to a value beyond $1.3 \mu \mathrm{m}$ ).

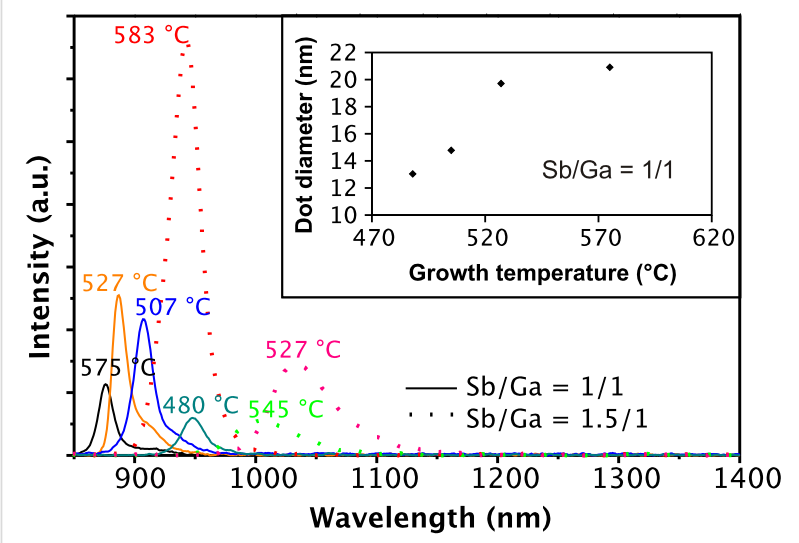

Figure 4: PL spectra of dots grown with a V/III ratio of $1 / 1$ and 1.5/1, but at different growth temperatures. The PL measurements were performed at a constant sample temperature of $T_{\mathrm{PL}}=20 \mathrm{~K}$. Inset: Dot diameter plotted against growth temperature for samples with a V/III ratio of $1 / 1$.

The dot diameter increased with increasing growth temperature, as shown for the smaller dots in the inset of Figure 4, in agreement with Forchel et al. [21]. The dot height also increased, while the dot density was almost constant at $\approx 6.5 \times 10^{10} \mathrm{~cm}^{-2}$. The experimental PL data were confirmed by numerical simulations with nextnano ${ }^{3}$, revealing a decrease of the Sb concentration with increasing growth temperature from $T=480$ up to $583{ }^{\circ} \mathrm{C}$. For the smaller dots the concentration dropped from $x=0.58$ down to $0.23\left(\mathrm{GaAs}_{0.42} \mathrm{Sb}_{0.58}\right.$ to $\left.\mathrm{GaAs}_{0.77} \mathrm{Sb}_{0.23}\right)$ in the mentioned growth temperature range, while for the larger dots the $\mathrm{Sb}$ content decreased from $x=0.52$ down to 0.31 $\left(\mathrm{GaAs}_{0.48} \mathrm{Sb}_{0.52}\right.$ to $\left.\mathrm{GaAs}_{0.69} \mathrm{Sb}_{0.31}\right)$.

Due to the lower Sb concentration the larger QDs emitted at a similar wavelength to those reported in [1-3,5-12], although those dots are much smaller. In other publications [13-16] QD emission as well as dimensions can be compared to our work.

According to Figure 2 an increase in the dot volume should lead to a redshift of the PL peak. However, the blueshift induced by the decreased $\mathrm{Sb}$ concentration in the QDs overcompensates for the volume dependent redshift, leading to the net blueshift observed in Figure 4.

\section{Quantum dot laser}

The reported results on highly uniform, dense lying GaAsSb QDs allowed the realization of an efficient QD laser. The device was electrically pumped and the growth parameters of the QDs in the active region were: V/III ratio of $1 / 1$ and a growth temperature of $T \approx 520^{\circ} \mathrm{C}$, leading to an emission wavelength around $0.900 \mu \mathrm{m}$, see Figure 5. The growth process started with a $200 \mathrm{~nm}$ thick n-doped GaAs buffer layer followed by a $1500 \mathrm{~nm}$ n-doped $\mathrm{Al}_{0.50} \mathrm{Ga}_{0.50} \mathrm{As}$ as lower cladding. The active region consisted of eight layers of GaAsSb QDs, separated by $50 \mathrm{~nm}$ thick GaAs barriers. As upper cladding a $1500 \mathrm{~nm}$ thick $\mathrm{p}$-doped $\mathrm{Al}_{0.50} \mathrm{Ga}_{0.50}$ As layer was then grown. The sample was capped with a highly p-doped $50 \mathrm{~nm}$ thick GaAs layer for optimized electrical contact.

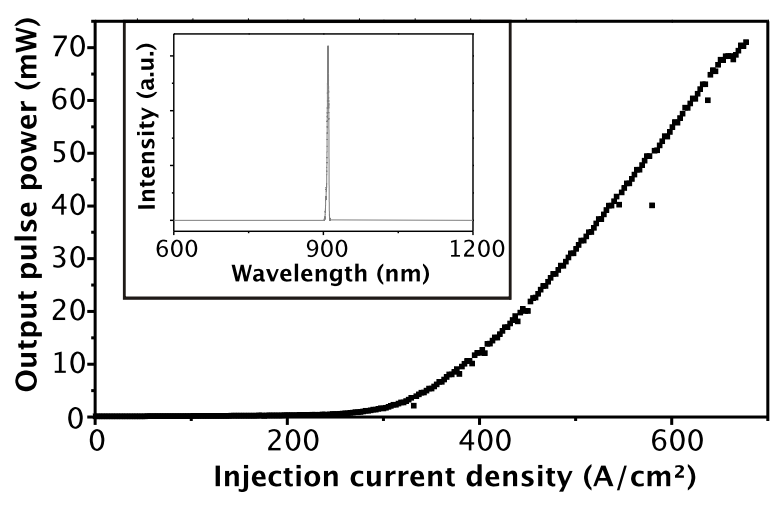

Figure 5: Output pulse power versus injection current density of a laser with a $1000 \mu \mathrm{m}$ long and $30 \mu \mathrm{m}$ wide active region, operated in pulsed mode ( $1 \mu$ s pulse width and a duty cycle of $0.1 \%)$ at an operating temperature $T_{\text {Laser }}=84 \mathrm{~K}$. The threshold current density and quantum efficiency were $j_{\text {th }}=356 \mathrm{~A} / \mathrm{cm}^{2}$ and $\eta_{d}=0.542$, respectively. The inset shows the emission spectrum at $j=1.22 \times j_{\text {th }}$ revealing an emission wavelength of $\lambda_{\text {Laser }}=0.909 \mu \mathrm{m}$. The cavity length and width were 1000 and $30 \mu \mathrm{m}$, respectively. At an operating temperature $T_{\text {Laser }}=84 \mathrm{~K}$ the laser was characterized by a threshold current density of $j_{\text {th }}=356 \mathrm{~A} / \mathrm{cm}^{2}$ and a quantum efficiency of $\eta_{d}=0.542$. (Lasing at room temperature was also observed, but with substantially less favourable parameters, i.e., $j_{\mathrm{th}}=3924 \mathrm{~A} / \mathrm{cm}^{2}$ and $\eta_{\mathrm{d}}=0.03$.)

The output pulse power versus pump current density characteristics, and the corresponding emission spectrum, are both shown in Figure 5. The emission wavelength of $\lambda_{\text {Laser }}=0.909 \mu \mathrm{m}$ (at $\left.j=1.22 \times j_{\text {th }}\right)$ is very close to the expected wavelength. From temperature dependent threshold current measurements, characteristic temperatures of $T_{0}=476.8 \mathrm{~K}$ for the temperature range below $140 \mathrm{~K}$, and $T_{0}=63.2 \mathrm{~K}$ above $140 \mathrm{~K}$, were extracted.

In principle, for different desired emission wavelengths the laser design can be kept constant, and only the QD character 
within the active region needs to be varied. With this concept GaAsSb QD lasers between 0.876 and $1.035 \mu \mathrm{m}$ emission wavelength can be achieved.

\section{Conclusion}

A very high GaAsSb QD density on GaAs of at least $6.5 \times 10^{10} \mathrm{~cm}^{-2}$ was achieved in the SK epitaxial growth mode, with a V/III flux ratio of $1 / 1$ at a growth temperature of $T=527^{\circ} \mathrm{C}$ and nominal coverage of $3 \mathrm{ML}$. With increasing $\mathrm{V} / \mathrm{III}$ ratio the dot size also increased. Only one PL peak was detected, attributable to the quantum dot nature; no further peak, relating to a wetting layer or otherwise, was observed. For a V/III ratio of $1 / 1$ (smaller dots) the PL peak was at $\lambda \approx 0.887 \mu \mathrm{m}$ for a growth temperature of $T=527{ }^{\circ} \mathrm{C}$ and a nominal coverage of $3 \mathrm{ML}$. The dots grown with a V/III ratio of $1.5 / 1$ (larger dots) exhibited a PL peak at $\lambda \approx 1.035 \mu \mathrm{m}$ and a smaller number density of $3.2 \times 10^{10} \mathrm{~cm}^{-2}$. Numerical simulations with the program nextnano ${ }^{3}$ revealed a $\mathrm{Sb}$ concentration within the QDs of $x=0.28\left(\mathrm{GaAs}_{0.72} \mathrm{Sb}_{0.28}\right)$ for the smaller dots and $x=0.52\left(\mathrm{GaAs}_{0.48} \mathrm{Sb}_{0.52}\right)$ for the larger dots.

Moreover, the growth temperature had a strong influence on PL emission wavelength. With precise control of the V/III ratio and growth temperature the PL peak positions of the QDs could be varied in a wide wavelength range from 0.876 to $1.035 \mu \mathrm{m}$. And the blueshift induced by the increased As concentration in the QDs, due to elevated growth temperatures, overcompensates for the redshift expected for increasing dot dimensions.

Finally, an electrically pumped QD laser with an emission wavelength of $0.909 \mu \mathrm{m}$, a threshold current density of $j_{\text {th }}=356 \mathrm{~A} / \mathrm{cm}^{2}$, and a quantum efficiency of $\eta_{\mathrm{d}}=0.542$ at a temperature of $84 \mathrm{~K}$ was successfully realized.

\section{Acknowledgments}

This work was supported by the "Deutsche Forschungsgemeinschaft" (German Science/Research Foundation) within the program "Graduiertenkolleg 792 - Nichtlineare Optik und Ultrakurzzeitphysik".

\section{References}

1. Tatebayashi, J.; Khoshakhlagh, A.; Huang, S. H.; Balakrishnan, G.; Dawson, L. R.; Huffaker, D. L.; Bussian, D. A.; Htoon, H.; Klimov, V. Appl. Phys. Lett. 2007, 90, 261115. doi:10.1063/1.2752018

2. Hatami, F.; Ledentsov, N. N.; Grundmann, M.; Böhrer, J.; Heinrichsdorff, F.; Beer, M.; Bimberg, D.; Ruvimov, S. S.; Werner, P.; Gösele, U.; Heydenreich, J.; Richter, U.; Ivanov, S. V.; Meltser, B. Ya.; Kop'ev, P. S.; Alferov, Zh. I. Appl. Phys. Lett. 1995, 67, 656-658. doi:10.1063/1.115193

3. Müller-Kirsch, L.; Heitz, R.; Pohl, U. W.; Bimberg, D.; Häusler, I.; Kirmse, H.; Neumann, W. Appl. Phys. Lett. 2001, 79, 1027-1029. doi:10.1063/1.1394715
4. Timm, R.; Eisele, H.; Lenz, A.; Becker, S. K.; Grabowski, J.; Kim, T.-Y.; Müller-Kirsch, L.; Pötschke, K.; Pohl, U. W.; Bimberg, D.; Dähne, M. Appl. Phys. Lett. 2004, 85, 5890-5892. doi:10.1063/1.1833560

5. Geller, M.; Kapteyn, C.; Müller-Kirsch, L.; Heitz, R.; Bimberg, D. Appl. Phys. Lett. 2003, 82, 2706-2708. doi:10.1063/1.1569413

6. Huang, S. H.; Balakrishnan, G.; Mehta, M.; Khoshakhlagh, A.; Dawson, L. R.; Huffaker, D. L.; Li, P. Appl. Phys. Lett. 2007, 90, 161902. doi:10.1063/1.2723649

7. Balakrishnan, G.; Tatebayashi, J.; Khoshakhlagh, A.; Huang, S. H.; Jallipalli, A.; Dawson, L. R.; Huffaker, D. L. Appl. Phys. Lett. 2006, 89, 161104. doi:10.1063/1.2362999

8. Laghumavarapu, R. B.; Moscho, A.; Khoshakhlagh, A.; El-Emawy, M.; Lester, L. F.; Huffaker, D. L. Appl. Phys. Lett. 2007, 90, 173125. doi:10.1063/1.2734492

9. Tatebayashi, J.; Khoshakhlagh, A.; Huang, S. H.; Dawson, L. R.; Balakrishnan, G.; Huffaker, D. L. Appl. Phys. Lett. 2006, 89, 203116. doi:10.1063/1.2390654

10. Hatami, F.; Grundmann, M.; Ledentsov, N. N.; Heinrichsdorff, F.; Heitz, R.; Böhrer, J.; Bimberg, D.; Ruvimov, S. S.; Werner, P.; Ustinov, V. M.; Kop'ev, P. S.; Alferov, Zh. I. Phys. Rev. B 1998, 57, 4635-4641. doi:10.1103/PhysRevB.57.4635

11. Glaser, E. R.; Bennett, B. R.; Shanabrook, B. V.; Magno, R. Appl. Phys. Lett. 1996, 68, 3614-3616. doi:10.1063/1.115747

12. Suzuki, K.; Hoog, R. A.; Arakawa, Y. J. Appl. Phys. 1999, 85, 8349-8352. doi:10.1063/1.370622

13. Wang, T.; Forchel, A. Appl. Phys. Lett. 1998, 73, 1847-1849. doi:10.1063/1.122302

14. Matsuda, K.; Nair, S. V.; Ruda, H. E.; Sugimoto, Y.; Saiki, T.; Yamaguchi, K. Appl. Phys. Lett. 2007, 90, 013101. doi:10.1063/1.2425039

15. Sun, C.-K.; Wang, G.; Bowers, J. E.; Brar, B.; Blank, H.-R.; Kroemer, H.; Pilkuhn, M. H. Appl. Phys. Lett. 1996, 68, 1543-1545. doi:10.1063/1.115693

16. Hogg, R. A.; Suzuki, K.; Tachibana, K.; Finger, L.; Hirakawa, K.; Arakawa, Y. Appl. Phys. Lett. 1998, 72, 2856-2858. doi:10.1063/1.121480

17. Müller-Kirsch, L. Metallorganische Gasphasenepitaxie und Charakterisierung von antimonhaltigen Quantenpunkten. Ph.D. Thesis, University of Technology Berlin, Germany, 2002.

18. Khreis, O. M.; Homewood, K. P.; Gillin, W. P.; Singer, K. E. J. Appl. Phys. 1998, 84, 4017-4019. doi:10.1063/1.368583

19. Birner, S.; Zibold, T.; Andlauer, T.; Kubis, T.; Sabathil, M.; Trellakis, A.; Vogl, P. IEEE Trans. Electron Devices 2007, 54, 2137-2142. doi:10.1109/TED.2007.902871

20. Wang, T.; Forchel, A. J. Appl. Phys. 1999, 86, 2001-2007. doi:10.1063/1.371000

21. Wang, T.; Forchel, A. J. Appl. Phys. 1999, 85, 2591-2594. doi:10.1063/1.369625 


\section{License and Terms}

This is an Open Access article under the terms of the Creative Commons Attribution License

(http://creativecommons.org/licenses/by/2.0), which permits unrestricted use, distribution, and reproduction in any medium, provided the original work is properly cited.

The license is subject to the Beilstein Journal of Nanotechnology terms and conditions:

(http://www.beilstein-journals.org/bjnano)

The definitive version of this article is the electronic one which can be found at:

doi:10.3762/bjnano.2.39 